\section{COMMUNITY BASED STUDY ON FAMILY RELATED CONTRIBUTORY FACTORS FOR CHILDHOOD UNINTENTIONAL INJURIES IN AN URBAN SETTING OF SRI LANKA}

DH Punyadasa, D Samarakkody. Ministry of Health, Sri Lanka

\subsection{6/injuryprev-2016-042156.696}

Background Childhood unintentional injuries are unexpected occurrences affecting a child, which lead to immeasurable grief and suffering to entire family. It is one of the leading causes of hospitalisation among children in Sri Lanka resulting death and disability. Children aged 1-4 years are at greater risk of unintentional injuries and majority of injuries among this age group occur in their family environment. Prevention of such injuries requires a clear understanding of their contributory factors.

Methods A community based descriptive cross sectional study was carried out among children aged 1-4 years residing in an urban setting of Sri Lanka, to assess the incidence and associated family related factors of unintentional injuries. 458 children were recruited using simple random sampling technique, giving a response rate of $91.6 \%$. Parents of selected children completed an interviewer administered questionnaire (IAQ) that recorded the parent's recollection of their child having an unintentional injury needed medical attention, within three months prior to the interview. Socio demographic factors and family related factors of the study subjects were also collected by the IAQ. The data was analysed using SPSS 18.2 statistical package.

Results The incidence of unintentional injuries during the study period of three months was 28.1 per 100 children $(95 \%$ CI = 19.46-36.74).

The factors that were significantly associated with the occurrence of unintentional injuries among children are low monthly income of the family ( $\mathrm{p}=0.045$ ), low social support to the mother of index child $(\mathrm{p}=0.022)$, non authoritative type of parenting of the mother of index child $(p=0.039)$, cared by person other than mother during day time $(\mathrm{p}=0.002)$, frequent arguments between parents $(\mathrm{p}=0.004)$ and frequent alcohol consumption of father $(\mathrm{p}=0.001)$.

Conclusions Unintentional injuries are an important child health issue among children aged 1-4 years. Identification of family related contributory factors for unintentional injuries among this age group will enable policy makers to formulate effective child injury preventive interventions.

\section{THE IMPORTANCE OF BIKE'S BRAKE ADJUSTMENT}

${ }^{1}$ Kimiko Deguchi, 2,3 Koji Kitamura, 2,3 Yoshifumi Nishida, ${ }^{2,3}$ Mikiko Oono, ${ }^{4,2,3}$ Tatsuhiro Yamanaka. ${ }^{1}$ Deguchi PaediatricClinic, Japan; ${ }^{2}$ National Institute of Advanced Industrial Science and Technology, Japan; ${ }^{3}$ Safe Kids Japan, Japan ; Ryokuen Children's Clinic, Japan

10.1136/injuryprev-2016-042156.697

Background Bicycle crashes are a major cause of injuries in childhood. According to injury data from the Bodygraphic Injury Surveillance System of the National Centre for Child Health and Development, bicycles are the number one product related to childhood injuries. Although it is important to keep one's brakes adjusted to prevent bicycle-related injuries, less attention has been paid to its importance compared to a helmet use. The purpose of this study is to measure the characteristics of children's hand growth and to reveal the relationship between a child's hand size and a reaction time to brake.
Methods Ten boys and 10 girls from each grade (120 students in total) participated in this study. To gather school children's anthropometric hand data, we measured the palm length, the middle finger length, and the length between the base of the thumb and the DIP of a middle finger. For the reaction time measurement, we prepared two bikes which attached the different size of width (standard or wide). Each participant rode both bikes and measured their reaction time. More specifically, the reaction time means the time from a participant notices the sign to stop to the time when the brake in the rear wheel begins to work. We considered the standard width as fit of one's hand size. Results The length of both the palm and the middle finger increased 1.2 times in 6 years of elementary school. The growth rates were bigger among students in 4, 5, 6 grades compared to students in 1, 2, 3 grades. When the brake lever width does not fit one's hand, the reaction time to brake is delayed by $0.1 \mathrm{sec}-$ ond. Moreover, we found the tendency that one required more reaction time to brake if one's hand size is small.

Conclusions We revealed the relationship between a child's hand size and a reaction time to brake and the importance of bike's brake adjustment. Based on the results from this study, we developed an animated video for bike safety. In future studies, we planned to implement an educational program to recommend a regular bike maintenance including a bike brake in addition to a helmet use.

\section{DEALING WITH DIVERSITY: CHILD INJURY PREVENTION STRATEGIES FOR A CULTURALLY DIVERSE WESTERN AUSTRALIA}

Katherine Celenza. Kidsafe Western Australia, Australia

\subsection{6/injuryprev-2016-042156.698}

Background Western Australia cannot be a one size fits all when it comes to child injury prevention, the size of the state and diversity of each region makes it important to have targeted and appropriate campaigns and resources. Perth is one of the most remote cities and the extent of the Western Australian state means that accessing parents and carers that are remote and isolated takes an important role in ensuring that resources and programs are targeted and specific to each region.

Description of problem Addressing a shortage of culturally appropriate information available for parents and carers of children on the prevention of common childhood injuries was the purpose of this program. Ensuring that messaging and resources specifically targeted high risk regional Aboriginal communities, were culturally appropriate and regionally specific to address the issue of child injury prevention in Western Australia. Kidsafe WA worked with individual regional and remote Aboriginal communities to adapt current programs and resources to specifically address each region and the injury issues associated. Ensuring messaging was specific, culturally appropriate and addressed local issues was key to targeting a diverse area.

Results This paper will outline what was learned through the consultation process undertaken with community members within regional Aboriginal communities throughout the Pilbara, Kimberley and Goldfields Region. It will focus on the strengths and weaknesses of existing practices, how the program has been evaluated and what the next step is in addressing the issues raised for reducing child injuries.

Conclusions The progression of this project towards a suite of resources available across WA has reinforced the need for 
targeted, specific resources, with a 'one size fits all approach' being inappropriate. Continued consultations with Aboriginal community groups throughout Western Australia has assisted in finalising resources and ensuring they are relevant and appropriate for use throughout Western Australia.

\section{COMMUNITY MOBILISATION TO ESTABLISH A COMMUNITY CRECHE TO INCREASE CHILD SUPERVISION IN RURAL NEPAL}

${ }^{1}$ Puspa Raj Pant, ${ }^{2}$ Matthew Ellis, ${ }^{1}$ Toity Deave, ${ }^{1} J u l i e$ Mytton. ${ }^{1}$ University of the West of England, Bristol; ${ }^{2}$ University of Bristol

\subsection{6/injuryprev-2016-042156.699}

Background Injuries are among the leading causes of death and hospitalisation of children worldwide; $90 \%$ of all injuries are unintentional. In 2010, over 900 children aged 1-4 years died from injuries in Nepal; the extent of non-fatal injuries is unknown. Most of the injuries to younger children occur at home, and associated with lack of supervision. Community mobilisation may be a feasible approach for preventing child injuries in rural Nepal. We describe community mobilisation for developing a community-crèche for 1-3 year old children to increase supervision and promote early childhood development.

Methods We worked with one women's group in Makwanpur and facilitated group discussion; a visit to an established crèche system in Bangladesh; did debriefing and orientation, and community involvement sessions. The women's group formed a committee to develop and manage the crèche; nominating 2 volunteers who were responsible for identifying eligible children and running the crèche. Published minimum standards for early child development centres (ECDC) by the government of Nepal were applied.

Results In February 2015, a crèche was established in Hatiya (Makwanpur) under the ownership of local women's group; and registered with local authority. A qualified ECD trainer trained the volunteers and mothers on stages of childhood development. A total of 17 children aged 1-3 years were enrolled and attended the crèche for 3 to 4 hours daily. Parents observed positive changes in children attending crèche. They also felt their children were in secure place when they were at work. The local municipality provided financial support to the crèche. A local government ECD centre agreed to intake the graduates from the crèche. Conclusion It is feasible, acceptable and potentially sustainable to establish crèches for young children in Nepal with full ownership of local women's group. There is very high potential for the partnership with local government which can also provide resources.

\section{0 \\ ROAD TRAFFIC INJURIES AMONG CHILDREN ATTENDED AT ER, YANGON GENERAL HOSPITAL}

Htun Nanda, Aung Thein Htay, Thit Lwin. Department of Orthopaedics and Trauma, University of Medicine 1, Yangon

\subsection{6/injuryprev-2016-042156.700}

Background As Myanmar is moving towards the socioeconomic development more accidents are happening amid increasing number of vehicles. There were very few studies regarding with childhood injuries in Myanmar and further studies and evaluation are required to get appropriate preventive measures for road traffic injuries in children.

Methods Hospital based cross-sectional descriptive study was conducted during the period of September 2013 to August 2014 at ER, Yangon General Hospital to recognise epidemiological distribution of RTA among children under 12 years of age. During this period, 350 cases attended at ER and data were collected from out-patient register and police record from Yangon General Hospital. Three sub-groups were defined by type of injured persons; pedestrian, non-motor vehicle and motor vehicle. Children were grouped into 3 categories depending on their age.

Results Among the injured, 63.1\% were pedestrians, 277\% were motor vehicle accidents and only 9.15 were nno-motor vehicle accidents. Among the age group school going age were commonest with $68.9 \%$ with male preponderance $59.4 \%$ and most of them $(71.1 \%)$ were from urban area.

Head and neck injuries were most common with $54.9 \%$ followed by lower limb injuries (27.4\%) and upper limb injuries $(17.7 \%)$. Soft tissue injuries $(57.4 \%)$ were common followed by fractures $20 \%$. There were 4 deaths and the cause of death ws head injury and multiple injuries.

Conclusion Childhood road traffic injuries are common in school going age group and most of them are pedestrians. Road safety measures for children and school environment should be encouraged for possible interventions. Road Safety education should be introduced into curriculum and early childhood education on road safety should be delivered.

\section{IMPACT ANALYSIS OF REVISION OF A JAPANESE SAFETY STANDARD OF BICYCLE WHEEL GUARD}

\begin{abstract}
${ }^{1,2}$ Koji Kitamura, 1,2 Yoshifumi Nishida, ${ }^{1,2}$ Mikiko Oono, 1,2,3 Tatsuhiro Yamanaka. 'National Institute of Advanced Industrial Science and Technology, Japan; ${ }^{2}$ Safe Kids Japan; ${ }^{3}$ Ryokuen Children's Clinic, Japan.
\end{abstract}

\subsection{6/injuryprev-2016-042156.701}

Background We contributed to the revision of a Japanese safety standard of bicycle wheel guard for preventing childhood injury due to wheel spoke, by showing the actual situation of the injury based on our injury data and clarifying reachable range of child's foot based on experimental measurement. In this study, the purpose is to evaluate impact of the revision based on our injury database.

Methods Our injury data base includes injured body part data which is recorded as 3 dimensional area data on the 3 dimensional child model by our developed system. The system can calculate the frequency distribution by overlaying multiple data. To evaluate the impact, we compared probability distribution of injury cases due to bicycle before and after the revision.

Results The number of cases before the revision is 325 and the number of cases before the revision is 159 . We compared them by calculating injured probability distribution of body parts. As for all injury cases due to bicycle, injured probability of knees and heels is reduced after the revision. As for injury cases of foot which is injured due to wheel spoke, average of injured probability is decreased by approximately $55.3 \%$ after the revision. The result indicates that the revision is effective for preventing injury due to wheel spoke.

Conclusions We evaluated impact of the revision at this time. We showed that we can evaluate impact of preventive measure quantitatively based on injury database. We think that the impact will increase because bicycle which is fulfilled the revised safety standard will become widespread over time. We will continue to 